PROCEDURAL JUSTICE, EMOTIONS AND COMPLIANCE

Running Head: PROCEDURAL JUSTICE, EMOTIONS AND COMPLIANCE

Procedural Justice Policing and Citizen Compliance Behaviour: The Importance of Emotion.

Julie M. Barkworth and Kristina Murphy

Griffith University, Brisbane, Queensland

Date: 19 February 2014

Author Note

Julie Barkworth and Kristina Murphy, School of Criminology and Criminal Justice, Griffith University.

Correspondence concerning this article should be addressed to Julie Barkworth, School of Criminology and Criminal Justice, Griffith University, Mt Gravatt, QLD 4122. Email: j.barkworth@griffith.edu.au 


\title{
Procedural Justice Policing and Citizen Compliance Behaviour: The Importance of
} Emotion.

\begin{abstract}
Research consistently finds that if authorities use procedural justice in encounters with the public then this will promote citizen cooperation and compliance with the law. Recently, the importance of people’s emotional reactions in response to procedural justice and injustice, and the subsequent effect this has on behaviour has been examined. This paper utilises a multi-method approach to examine the mediating role that negative affect plays in the effect of procedural justice policing on citizen compliance behaviour. Study 1 utilises both crosssectional and longitudinal field survey data collected from Australian citizens who have had a recent contact with a police officer. Study 2 utilises an experimental vignette study designed to assess the causal mechanisms involved in the procedural justice-emotion-compliance relationship. Both studies find that procedural justice is linked to people's self-reported propensity to comply with police. Study 1 and 2 also find that negative affect mediates this relationship. These findings have important implications for training police to interact with the public in a manner that reduces negative emotions and ensures the highest level of compliance from the public.
\end{abstract}

Keywords: procedural justice; emotions; compliance; police; behaviour 


\section{Introduction}

How and why people cooperate and comply with authority figures has emerged as a significant field of study over the past several decades. Some of this research has specifically examined the concept of procedural justice in producing compliance-related behaviour in relationships between employees and employers (e.g., Rankin \& Tyler, 2009), customers with service organisations (e.g., Chebat \& Slusarczyk, 2005), taxpayers with tax authorities (e.g., Murphy, 2005; Worsham, 1996), and prisoners with prison guards (e.g., Henderson, Wells, Maguire \& Gray, 2010). Social psychologists and criminologists have also been particularly interested in understanding what makes people cooperate and comply with police and the law (e.g., Tyler 2006; 2011; Murphy, Hinds \& Fleming, 2008).

Leading scholars in the field of procedural justice argue that people react strongly to how they are treated by authorities, and that their decision to comply with those authorities may be altered as a result of the treatment they receive (e.g., Bradford, Jackson, \& Stanko, 2009; Murphy et al., 2008; Sunshine \& Tyler, 2003; Tyler \& Huo, 2002). Research has demonstrated that when people are treated with trust, respect, neutrality, and are given an opportunity to express their views - all aspects of procedural justice - they are more likely to comply with directives, rules, and laws, and are more likely to voluntarily cooperate with authorities (e.g., Braithwaite \& Makkai, 1994; Jackson \& Bradford, 2010; Johnson, 2004; McCluskey, 2003; Murphy et al., 2008).

An emerging field of research has been interested in exploring the potential relationship between procedural justice and emotions, and the impact of this relationship on behavioural reactions to requests from authorities (for a review see Cropanzano, Stein \& Nadisic, 2011). The discrete emotions of happiness, joy, anger, frustration, guilt, and anxiety have all been linked to perceptions of procedural justice and injustice (e.g., Krehbiel \& Cropanzano, 2000; Weiss, Suckow, \& Cropanzano, 1999). Yet only a limited number of studies have specifically examined whether emotions mediate the effect of procedural justice on subsequent behavioural reactions (see Chebat \& Slusarczyk, 2005; Gordjin, Yzerbyt, Wigboldus, \& Dumont, 2006; VanYperen, Hagedoorn, Zweers, \& Postma, 2000). Furthermore, only one study has examined whether emotions mediate the relationship between procedural justice and legal compliance behaviour (see Murphy \& Tyler, 2008).

Using a multi-method approach, the present study aims to extend research in this field. Using survey data in Study 1 and a vignette experiment in Study 2 this paper aims to examine the importance of procedural justice in shaping people's willingness to obey the 
police and the law, and more importantly, whether negative emotions play a mediating role in this relationship.

\section{Procedural Justice, Emotions, and Compliance}

Four constructs are often defined as the underlying features of procedural justice: trustworthiness, respectful treatment, neutrality, and voice (Rankin \& Tyler, 2009; Tyler, 2008; Tyler \& Huo, 2002; Tyler \& Murphy, 2011). Trustworthiness refers to public perceptions of how motivated an authority is to be caring, open, and honest, while serving the best interests of the community (Tyler, 2008). Respectful treatment involves engaging individuals with respect, dignity, politeness, professionalism, and seriousness (Tyler, 2008). Neutrality requires every case be handled in the same manner and to follow the same process each time, regardless of who is involved (Tyler, 2008). Finally, voice represents whether an authority gives an individual an opportunity to explain or justify their situation, express their viewpoint about an issue, and contribute to the decision-making process (Potter, 2005, p.51). These four components of procedural justice have been found to be important for eliciting compliant behaviour in a range of contexts, including in police-citizen interactions (e.g., Dai, 2007; Jackson \& Sunshine, 2007; Johnson, 2004). Understanding why this relationship exists is clearly important.

Social psychological research suggests that procedural justice enhances identification with groups, and it is this identification process that predicts compliant behaviour.

Specifically, the Group Engagement Model (Tyler \& Blader, 2003) in the procedural justice literature suggests that people want to belong in society and that they value group membership. The Group Engagement Model also suggests that being treated with procedural justice communicates to people that they are valued and respected members of society, while rude and disrespectful treatment indicates exclusion from a group (Murphy \& Tyler, 2008). Authorities such as police are important representatives of society. They represent the norms and values of society and they enforce these norms and values through laws. Hence, when police - as representatives of society- use procedural justice, they reaffirm a sense of 'group identity’ or societal membership among citizens (see Bradford, Murphy \& Jackson, 2013). When citizens are treated with respect and fairness by the police their social standing within society is therefore upheld, encouraging allegiance to group norms and a willingness to cooperate and comply with group laws and authorities.

While an important theoretical framework, the Group Engagement Model does not adequately explain why social identity processes may result in retaliatory or non-compliant 
behaviour in some circumstances but not others. For example, why is it that people who are treated unfairly do not always retaliate against such unfair treatment? Perhaps it is the emotion elicited from unfair treatment that determines the behavioural response taken. Recent literature has started to focus on the possible role that emotions play in the procedural justice-compliance relationship. Research on this topic in the context of policing has not yet been explored, but several studies in other contexts have found links between procedural justice and positive emotions and between procedural injustice and negative emotions. For example, researchers have found the emotion of happiness to be linked with experiences of procedural justice, and emotions such as anger and frustration to be linked with procedural injustice (Weiss et al., 1999; Krehbiel \& Cropanzano, 2000).

A small number of studies have explored the mediating role of emotion in predicting attitudinal and behavioural responses. Of the few studies that have examined this issue, it has been shown that emotion is an important mechanism for explaining the impact of procedural justice on attitudes and behaviour. For example, Chebat and Slusarczyk (2005) surveyed a sample of consumers who had made a complaint against a Canadian bank in the previous year. The authors were interested in the loyalty-exit behaviour of consumers as a result of having experienced procedural justice. Also of interest was the loyalty-exit behaviour as a result of emotions experienced due to perceived justice. Results showed that consumers who had made a complaint did not necessarily remain loyal after the issue was resolved if their emotions had not been properly attended to. It was found that loyalty-exit behaviour was linked to justice concerns through both positive and negative emotions experienced (Chebat \& Slusarczyk, 2005). Similarly, Schoefer and Diamanatopolous (2008) examined the importance of perceived justice and emotions on post-complaint behaviour for service companies (e.g., travel agents, airlines). Using survey data, the authors found consumers' repurchase intentions were linked to perceptions of procedural justice, which was mediated by positive and negative emotions. Those who felt they had been treated fairly were more likely to make future purchases from the company they had filed a complaint against. Furthermore, it was found that when individuals perceived they had been treated unfairly they were more likely to experience emotions such as anger and frustration, which led to an increased likeliness of negative word-of-mouth.

Another study in a workplace setting examined destructive behavioural intentions (i.e., exit, neglect, and aggressive voice) of nurses in South Africa. The study found that those who felt their work supervisor had not listened to their concerns were more likely to experience higher levels of negative affect (e.g., anger, fear, misery, resistance, nervousness), 
and were more likely to engage in destructive behaviours (VanYperen et al., 2000). The authors also found that employees were much more likely to leave their place of employment when negative feelings resulted from the belief that procedural injustice had led to an unfavourable outcome (for similar findings see De Cremer \& Den Ouden, 2009). Together, these studies demonstrate that positive and negative emotions can mediate the relationship between procedural justice and subsequent behavioural reactions.

Only one published study to date has explored this relationship within a law enforcement setting (Murphy \& Tyler, 2008). Murphy and Tyler (2008) analysed longitudinal survey data from 652 Australian taxpayers involved in a taxation dispute with the Australian Taxation Office (ATO) to illustrate that negative emotions (i.e., anger) can be influenced by perceptions of procedural injustice and that these emotional reactions can mediate the effect of procedural injustice on subsequent tax compliance behaviour. Murphy and Tyler found that taxpayers were more likely to feel anger when they believed the ATO had dealt with their enforcement process in a procedurally unfair manner. Furthermore, those with greater perceptions of procedural injustice were more likely to indicate having evaded their taxes two years later. However, when anger levels of taxpayers were considered, the effect of procedural injustice on tax non-compliance behaviour disappeared, suggesting the effect of procedural injustice on compliance was mediated by the emotion of anger. Although Murphy and Tyler found support for the mediating role of emotions in the procedural justice/compliance relationship in a legal setting, their study did contain a noteworthy limitation. The taxation setting involved participants receiving enforcement letters from the ATO. Few taxpayers had a personal interaction with an ATO officer. Hence, the interpersonal treatment from the authority could not be adequately evaluated in relation to citizen reactions. Importantly, few of the emotion studies cited above provided a theoretical discussion about why emotions may be relevant to the procedural justice-compliance relationship. To suggest that emotions are the mechanism through which procedural justice acts on compliance requires a theoretical justification for why this may be so.

The criminological literature contains a number of theories that explain how and why procedural justice might be linked to compliance through emotion. While not specifically couched within the procedural justice literature, these theories can be used to demonstrate why procedural justice might have the effect it does on compliance behaviour. Agnew's (1992, 2001) general strain theory, for example, considers unjust treatment (i.e., procedural injustice) to be a form of subjective strain. The theory suggests that when people perceive different forms of strain, this strain can result in negative emotional responses. These 
negative emotions are considered conducive to crime, with crime or delinquency likely to result from such a response. Agnew argues that strainful events or conditions are more likely considered unjust when there is a "voluntary and intentional violation of a relevant justice norm” (2001, p. 329). He further suggests that strain in the form of unfair treatment might be especially likely to result in delinquency because this type of strain is more likely to elicit emotions conducive to crime, such as anger.

Adams' (1965) equity theory is another theoretical framework suggesting that emotion may mediate the relationship between procedural justice and compliance. Adams’ equity theory argues that perceptions of injustice rise from feelings of inequity between two parties when outcome/input ratios are not equal. When one experiences feelings of disadvantage, a negative emotional response such as anger is expressed. The tension (and distress) resulting from inequity motivates an individual to restore equity or reduce inequity, often through retaliatory behaviour. Whilst equity theory has most often been applied to distributive justice (i.e., the unequal distribution of treatment or services), the theory has been put forth as being relevant to procedural justice. Skarlicki and Folger (1997, p.45), for example, suggest that 'the anger and resentment associated with perceptions of unfair procedures may energize individuals to engage in retaliation'.

Braithwaite’s Reintegrative Shaming Theory (Braithwaite, 1989), and Sherman’s Defiance Theory (Sherman, 1993) also place emotion as a central mediator between authority treatment of offenders and offender's future compliance decisions. Hence, future procedural justice research may benefit from integrating emotion into theoretical perspectives that explain why procedural justice has a positive impact on people’s legal compliance behaviour.

\section{The Present Study}

The main aim of the present study is to test whether negative emotions can mediate the effect of procedural injustice on compliance-related behaviour in a law enforcement setting. Policing has been chosen as the contextual setting as it involves a legal authority (i.e., police officers) that many citizens in the community come into contact with. In Australia, for example, the current population of the State of Queensland is approximately 4.7 million people. Queensland Police Service (QPS) reported in excess of 5 million public interactions for the period 2010-11, including over 1,000,000 traffic infringements being issued (QPS annual report, 2011). While prior research supports the mediating role of emotions in the procedural justice compliance relationship, no study has explored this relationship in the policing context. Research within this context is important to assess whether emotion is one 
of the key mechanisms via which citizens translate unfair treatment from police into subsequent uncooperative and non-compliant behaviour.

The current study will utilise a multi-method design. The majority of studies cited above relied on cross-sectional field surveys to show that emotions mediated the effect of procedural justice on behaviour. While demonstrating the real world applicability of the relationship between procedural justice, emotions and behaviour, such a methodology can be criticised on two fronts: first, for assessing people's subjective perceptions of procedural justice (the objective nature of fair versus unfair procedures cannot be controlled for in such a setting); and second, the causal direction between procedural justice, emotion and compliance behaviour cannot be determined using cross-sectional survey data.

In addition to utilising cross-sectional survey data in the present study (Study 1), we also utilise panel survey data in Study 1, and employ an experimental design in which procedural justice is manipulated between groups (Study 2). The panel data and experimental methodology allow us to more successfully address the causal mechanisms involved in the procedural justice, negative emotion and compliance relationship. The current study also considers the interaction between police and citizens after a personal face-to-face encounter has occurred, allowing for a more accurate understanding of the effects of interpersonal treatment on emotion and compliance. Based on research conducted to date, we expect that perceptions of police use of procedural justice will lead to lower levels of negative affect (Hypothesis 1) and higher rates of compliance (Hypothesis 2), while perceptions of procedural injustice will lead to increased feelings of negative affect and lower levels of compliance. It is further hypothesised that the effect of procedural justice on compliance behaviour will be mediated by negative emotion (Hypothesis 3).

\section{Study 1 - Field Survey Data \\ Method}

\section{Participants and Procedure}

Study 1 utilises both cross-sectional and longitudinal survey data. In 2007, a sample of 5700 Australian citizens was randomly selected from the publicly available Electoral Roll $^{1}$ (the sample was stratified by State and Territory jurisdiction), and were sent a mail survey about crime and safety in their neighbourhood. The survey was accompanied by a reply paid envelope and covering letter that outlined the aims of the study and guaranteed

\footnotetext{
${ }^{1}$ All Australian citizens over the age of 18 are required by law to register their name and address on the Australian Electoral Roll.
} 
confidentiality. Three reminder letters (including a replacement questionnaire with the $2^{\text {nd }}$ reminder) were sent to non-responders over the course of three months, using identification numbers attached to questionnaires that were linked to the sample name. A total of 2120 useable surveys were returned. When adjusted for citizens who did not reside at the address listed on the Electoral Roll $(N=438)$, an adjusted response rate of $40.3 \%$ was obtained. The sample was tested for representativeness to the overall Australian population using 2006 Census data, and it was found to be broadly representative on a range of demographic measures (see XXX, 2010a).

In 2009, Wave 1 survey respondents were sent a copy of a follow-up survey ${ }^{2}$. The Wave 2 survey was again sent with a replied paid envelope and a covering letter which outlined the aims of the study and reminded respondents of initial participation in the first survey. Four reminder letters were sent to non-responders over the course of three months, and a total of 1204 surveys were returned. An adjusted follow-up response rate of $64.9 \%$ was achieved. Seven cases were excluded due to significant levels of missing data. Data from the Wave 1 and 2 surveys were then merged to allow for longitudinal analysis. A further seven cases could not be included due to identification labels being removed, resulting in a final panel sample size of 1190 (see XXX, 2010b).

From the total respondents $(N=1190)$ who had completed both waves of the survey, those who indicated they had had contact with police in the preceding 12-month period were of interest to the present study. At Time 1, 401 of the 1190 respondents indicated they had personal contact with police in the preceding 12-month period. At Time 2, 468 indicated they had personal contact with a police officer in the preceding 12-month period. Importantly, neither of these samples differed substantially from the full sample on a variety of demographic variables (see Table 1).

[insert Table 1 about here]

\section{Measures}

Study 1 used three multi-item scales from the survey: procedural justice, negative affect, and self-reported non-compliant behaviour. All items used to construct these scales were measured on a 1 (strongly disagree) to 5 (strongly agree) Likert Scale (see Table 2 for wording of these items). Perceptions of procedural justice were measured with a 5-item scale,

\footnotetext{
${ }^{2}$ Thirty-two respondents from the Wave 1 survey were not sent a follow-up survey due to them having removed their unique identification number from their Wave 1 survey booklet.
} 
with each of the four subcomponents of procedural justice being assessed. Respondents were asked to indicate how they felt they were treated in their most recent contact with police; a higher score on this scale represents greater perceptions of being treated with procedural justice. Respondents' negative emotions in response to their recent interaction with police were also recorded to construct a 5-item negative affect scale; a higher score indicates greater levels of negative affect. Self-reported non-compliance behaviour was measured with a 3item scale. Respondents were asked to describe their willingness to obey police and the law, with a lower score indicating increased propensity for non-compliance. Procedural justice and negative affect were measured at both Time 1 and 2, while compliance was measured at Time 2 only. Participant demographics recorded at Time 2 were also included in the analyses, consisting of age, gender ( 0 = male; 1 = female), education level, and income.

\section{Results}

\section{Factor Analysis and Correlation Matrix}

A principal components factor analysis using varimax rotation was conducted on the Time 2 data to examine the conceptual differences between the three categories of variables analysed (procedural justice, negative affect, compliance). As can be seen in Table 2, all items loaded as expected onto their relevant factors. Table 3 presents means, confidence intervals and Cronbach alpha reliability scores for these three scales at both Time 1 and 2.

[insert Table 2 about here]

[insert Table 3 about here]

\section{Regression Analyses}

To explore whether negative emotions mediate the effect of procedural justice on compliance behaviour in the policing context, we undertook two sets of analyses. The first set of analyses utilised the Time 2 cross-sectional survey data. The second set of analyses utilised Time 1 and 2 longitudinal survey data to ascertain if the effects could be obtained over time. For mediation to occur, Baron and Kenny (1986) state the following four conditions should be met: 1) the independent variable (i.e., Procedural Justice) should be related to the mediator (i.e., Negative Affect); 2) the independent variable should be related to the dependent variable (i.e., Compliance); 3) the mediator should be related to the dependent variable; and 4) the previously significant relationship between the independent variable and the dependent variable should no longer be significant after controlling for the mediator. 
Cross-sectional analysis: Time 2 survey data

The first regression using the cross-sectional survey data used demographic variables and procedural justice to predict negative affect. The second hierarchical regression used demographic variables, procedural justice and negative affect to predict compliance. Only those respondents who reported having personal contact with police in the 12-month period preceding the Time 2 survey were used in the analysis $(N=468)$. As seen in Table 4 , age played a significant role in levels of negative affect experienced, with older individuals being less likely to experience heightened levels of negative affect. However, procedural justice was found to be a stronger predictor of negative affect, with those who perceived police as treating them fairly being less likely to express negative affect.

[insert Table 4 about here]

For the second analysis, Step 1 of Table 5 shows that age and education were significant predictors of compliance behaviour. Older and less educated respondents reported a greater propensity for compliance. Procedural justice was also a significant predictor of compliance. Although a weak relationship, those respondents who felt they had been treated more fairly by police were more likely to report a propensity for compliance. Of particular interest is the finding that negative emotion appears to mediate the effect of procedural justice on compliance behaviour. When Negative Affect was entered into the model at Step 2, it was revealed that negative emotions predicted propensity for non-compliance. Those who felt more negative emotion in response to police treatment were less compliant. Importantly, at Step 2 the relationship between procedural justice and compliance was no longer significant. This suggests that negative affect is a mechanism that can explain why procedural injustice has an influence on non-compliance. The mediating role of negative affect was confirmed with a Sobel test, $z=2.15, p=.03$. Therefore, the cross-sectional analyses demonstrate negative affect can fully mediate the relationship between procedural justice and compliance behaviour.

[insert Table 5 about here]

\section{Longitudinal analysis: Time 1 and 2 survey data}

The majority of the procedural justice studies cited in the Introduction utilised cross-sectional survey data (the exception being Murphy \& Tyler, 2008). When using cross-sectional data 
the causal mechanisms involved in the procedural justice, emotion, and compliance relationship can be obscured. Longitudinal data provides a stronger test of the causal relationships between variables. As such, longitudinal data was also analysed here to examine the causal relationship between the variables of interest. The first of the two longitudinal regression analyses used demographic variables and procedural justice measured at Time 1 to predict the level of negative affect experienced at Time 2, while controlling for respondents' level of negative emotion felt at Time 1. Again, only respondents who had had personal contact with a police officer in the 12 months preceding the Time 1 survey were included in the analysis $(N=401)$. Results, as seen in Table 6 , show negative affect and procedural justice at Time 1 were significant predictors of negative affect at Time 2. Those who reported experiencing negative affect at Time 1 were more likely to report experiencing negative affect at Time 2. Furthermore, those who felt they had been treated fairly by police during an encounter at Time 1 were less likely to experience negative affect at Time 2. Importantly, procedural justice was the stronger predictor of Time 2 negative affect. These findings suggest a causal relationship between procedural injustice and negative emotion.

[insert Table 6 about here]

The following hierarchical regression used demographic variables, procedural justice at Time 1, and negative affect at Time 2 as predictors of Time 2 compliance, while also controlling for the level of negative emotion experienced at Time 1. As shown in Step 1 of Table 7, only Time 1 procedural justice predicted Time 2 compliance behaviour. Those who perceived the police as being procedurally fair at Time 1 were more likely to comply with the law in the future; negative affect at Time 1 did not predict compliance at Time 2 . When negative affect at Time 2 was entered at Step 2, it was found to significantly predict Time 2 compliance behaviour. Respondents who experienced less negative emotion at Time 2 as a result of their police interaction were more likely to indicate they would comply with the law, even when negative emotions experienced at Time 1 were controlled for.

Of particular interest is the finding that Time 2 negative affect appeared to mediate the effect of Time 1 procedural justice on Time 2 compliance behaviour. In fact, procedural justice ceased to be a significant predictor of Time 2 compliance. This mediation was confirmed with a Sobel test, $z=2.53, p=.01$. Hence, in the longitudinal analyses negative emotions were shown to also fully mediate the relationship between procedural justice and 
compliance behaviour, thereby replicating the findings of Murphy and Tyler (2008) and the cross-sectional analyses reported earlier.

[insert Table 7 about here]

\section{Study 2 - Experimental Data}

Given the limitations associated with using field survey data (i.e., the time elapsed between Time 1 and 2 responses; errors in recall; the fact that procedural justice can be subjectively interpreted; and that true causality cannot be determined even with panel data), Study 2 uses an experimental vignette design to test whether negative emotions mediate the causal effect of procedural justice on compliance behaviour. An experimental design allows us to manipulate the delivery of procedural justice and injustice in a carefully controlled environment. By doing so, one can determine the true causal relationship between the variables of interest.

\section{Method}

\section{Design}

Study 2 utilised a between-groups experimental design. Independent variables included participant demographics and procedural justice (procedural justice vs. procedural injustice); dependent variables were negative affect and self-reported compliance with police and the law. Negative affect also served as a mediating variable. Vignettes designed for this study manipulated procedural justice so that participants experienced either procedurally fair or procedurally unfair treatment during a police-stop encounter. Participants were asked to imagine themselves being stopped by a police officer for exceeding the speed limit by $5 \mathrm{~km}$ per hour. Procedural justice was manipulated through three key components (trustworthiness, respectful treatment, and voice $)^{3}$. For example, in the procedural justice condition the police officer is courteous, friendly, explains their decision to pull over the driver, and allows the driver to explain the reason for their non-compliance with road rules. In the procedural injustice condition, in contrast, the police officer is condescending to the driver, uses rude and disrespectful language, does not explain to the driver the reason they were pulled over, and does not give the driver the opportunity to explain their situation.

\footnotetext{
${ }^{3}$ The procedural justice concept of neutrality could not be assessed in a between-groups study as this concept implies everyone receives equal treatment which is not possible when manipulating fair vs. unfair treatment.
} 


\section{Participants}

First-year psychology students of Griffith University in Brisbane, Australia were able to sign up for Study 2 in order to receive course credit. Additional members of the Griffith community were also contacted via a social network site or via email inviting them to complete a 20-minute online-survey about the attitudes people have toward police in Australia. A total of 170 completed surveys were received. However, 10 surveys were excluded due to significant amounts of missing data, and a further 12 participants were excluded due to failing a manipulation check. The manipulation check was used to ascertain whether the respondents had correctly interpreted the type of treatment they had received in each vignette ('Did the police officer treat you politely and respectfully?' Yes/No). The final sample of 148 respondents ( $N=72$ procedural justice condition; $N=76$ procedural injustice condition) ranged from 17 - 56 years (Mean Age = 24.90; $S D=8.22$ ), with 78.4\% females. Of these, 113 were university students. Further checks on the data revealed no demographic differences between respondents across the vignette conditions.

\section{Procedure}

All participants were provided with a link to an online-survey that randomly directed them to either the procedurally fair or procedurally unfair vignette condition. Participants were then asked to complete a 100-item survey assessing how they viewed the scenario they had just read. Participant demographics and general questions about police, and self-reported compliance behaviours were also assessed.

\section{Measures}

Two dependent variables (Negative Affect; Compliance) were utilised in Study 2 to assess whether procedural justice had an effect on negative emotion and self-reported compliance behaviour. We constructed a procedural justice dummy variable ( $0=$ procedural injustice; $1=$ procedural justice) to represent the experimental manipulation. To measure compliance, respondents were asked to indicate the likelihood of future compliance with the law as a result of the treatment they had received from the police during the encounter described in the vignette. The four-item compliance measure utilised a 5-point response format with a higher score indicating a greater propensity for compliance $(M=3.46$; $S D=0.88$; Cronbach alpha $=$ 0.90). A 5-item negative affect measure also used a 5-point response format for respondents to indicate the level of negative emotion sparked as a result of the hypothetical encounter they had experienced; a higher score represented heightened negative affect $(M=3.15$; $S D=$ 
1.14; Cronbach alpha $=0.92)$. The negative affect items in Study 2 were identical to those in Study 1 . Table 8 presents a principal components factor analysis listing and differentiating the items used to construct the negative affect and compliance scales. Participant demographic variables were also measured (age, gender ( 0 = male; $1=$ female), and income). As the majority of the sample utilised for Study 2 were university students, education level was not included in the following regression analyses.

[insert Table 8 about here]

Results

Table 9 presents marginal means and confidence intervals for negative affect and compliance, for respondents in the procedural justice and procedural injustice conditions. Two regression analyses that mirrored the cross-sectional analyses conducted in Study 1 were used to further examine whether negative affect mediates the relationship between procedural justice and compliance behaviour in an experimental design. Tables 10 and 11 demonstrate that the findings of Study 1 were replicated using a more controlled manipulation of procedural justice. As can be seen in Table 10, none of the demographic variables predicted negative affect. Procedural justice was the only significant predictor of this variable. Respondents in the procedural injustice condition were significantly more likely to experience negative affect than those in the procedural justice condition.

[insert Table 10 about here]

The following hierarchical regression also replicated the mediation effect found in Study 1. As shown in Step 1 of Table 11, procedural justice was found to significantly influence self-reported compliance behaviour; those in the procedural justice condition were more likely to report they would comply in the future than those in the procedural injustice condition. When negative affect was added to the Model at Step 2, however, the relationship between procedural justice and compliance became non-significant. Instead, negative affect became the only predictor of propensity to comply with the law. Those who reported feeling more negative emotion as a result of their encounter with the police officer were significantly more likely to report a propensity for non-compliance. This finding again suggests that negative affect fully mediates the relationship between procedural justice and compliance. A Sobel test confirmed this mediation effect, $z=2.51, p=.01$. Hence, Study 2 further supports 
the results found in Study 1 and those reported by Murphy and Tyler (2008). Negative emotion appears to mediate the effect of procedural justice on compliance in both field and experimental contexts.

[insert Table 11 about here]

\section{Discussion}

The aim of the present study was to examine whether negative emotions mediate the relationship between procedural justice and compliance behaviour. Previous research has shown that procedural justice has a positive influence on compliance behaviour (e.g., Chebat \& Slusarczyk, 2005; Rankin \& Tyler, 2009), including in the policing context (e.g., Tyler, 1990; Jackson, Bradford, Hough, Myhill, Quinton \& Tyler, 2012). Policing research suggests that if police employ procedural justice when interacting with the public, then citizens will be more willing to comply with police directives and engage in long-term voluntary compliance behaviour. On the flip side, research has also shown that when police use heavy-handed tactics or display rude and demeaning behaviour towards people (i.e., procedural injustice), this is more likely to result in citizen resistance, an escalation of violence and a nonwillingness on the part of citizens to cooperate or comply with police in the future (Mastrofski, Reisig \& McCluskey, 2002; McCluskey, 2003). The current study extends this research by exploring whether people's emotions are an important mechanism for explaining why procedural justice shapes compliance-related behaviour. Certainly, the criminology literature points to the value of researchers considering people's emotions when explaining defiance or criminal behaviour (Sherman, 1993). Exploring the relevance of emotion in the procedural justice literature is therefore worthwhile and provides an advance in theorizing in the procedural justice field.

Three hypotheses were tested in the present study. Hypothesis 1 sought to test whether receiving procedural justice from police reduces negative affect. Hypothesis 2 sought to test whether procedural justice promoted self-reported compliance. Hypothesis 3 tested whether negative emotions mediated the effect of procedural justice on self-reported compliance behaviour.

Utilising both a cross-sectional and longitudinal survey design, as well as an experimental vignette study, we found remarkably consistent findings across studies and methodologies. Hypothesis 1 was supported in both Study 1 and Study 2. We found that 
procedural justice reduced feelings of negative affect. If people believed they had been treated with procedural justice during a recent encounter with a police officer, they were less likely to experience negative emotions such as anger, anxiety or frustration. These findings support previous research linking negative emotions to procedural injustice (e.g., Weiss et al., 1999), hence supporting the idea that unfair treatment can lead to negative emotional reactions. The present study also replicated the well-established link in the policing literature between procedural justice and compliance behaviour (e.g., Tyler, 1990; Jackson et al., 2012). In both Study 1 (field surveys) and Study 2 (experiment), participants who felt they had received procedurally just treatment from police were less likely to report they would be non-compliant. Hence, Hypothesis 2 was supported in the present study. Importantly, this study has shown for the first time in the procedural justice literature that negative emotions can mediate the effect of procedural justice policing on citizen's compliance behaviour. This was found consistently for both Study 1 and 2, and supports Hypothesis 3. These findings support other results in the literature finding that negative emotions can mediate the relationship between procedural justice and subsequent attitudes and behaviours (e.g., Murphy \& Tyler, 2008; Chebat \& Slusarczyk, 2005; Schoefer \& Diamanatopolous, 2008; VanYperen et al., 2000).

\section{Implications of this research}

The results of the present study have demonstrated the importance of police engaging with the public with procedural justice so as to reduce negative emotions and increase law-abiding behaviour. The findings from the current study have important practical and theoretical implications. Most notably, procedural justice appears to be consistently important for influencing both emotional reactions and compliance behaviour. This is important because police can easily tailor the way in which they deal with citizens when they have contact with them. Police are not always in a situation where they can provide a favourable outcome, but they can choose to treat people in a procedurally fair manner. The results of this study show the value of such an approach being utilised by police. By engaging with the public in a polite, respectful and empathetic manner, police officers will be able to reduce negative sentiments and emotion directed at them, thereby increasing people's willingness to comply with them both immediately and in the future.

The results also have implications for theory development in the field of procedural justice research. As noted in the Introduction, the positive effect of procedural justice on compliance behaviour has often been explained by social psychologists using a social identity 
perspective. According to the Group Engagement Model, for example, people value group membership (Tyler \& Blader, 2003). When important group representatives such as police treat them with procedural justice it reaffirms their shared sense of purpose and identification with society, thereby encouraging allegiance to group norms and values. According to the model, a disconnect from the group as a result of unfair treatment is likely to lead to a decreased willingness to comply with the norms of that social group because it reduces identification with the group and results in marginalisation and alienation.

The social identity perspective has been particularly influential within the procedural justice literature. Yet we know from a number of criminological theories that emotion plays a very important role in explaining defiance and resistance to authority (see Braithwaite, 1989; Agnew, 1992; Adams, 1965; Sherman, 1993). How then, can both an identity and emotion perspective be aligned within one explanatory framework?

The common idea within the emotion literature is that events can be appraised as either harmful or favourable to one’s own goals or desires, and specific emotions are experienced as a result of this appraisal (e.g., Giner-Sorolla, Mackie \& Smith, 2007; Mackie, Devos \& Smith, 2000; Smith, 1993). Anger, for example, is argued to result from the appraisal that another person or group is harming or threatening the self, resulting in retaliative action (Mackie et al., 2000, p.602). Perceptions of unfair treatment by an authority might therefore lead individuals to perceive their identity and standing in a group is being challenged and threatened. This identity threat in turn might spark a negative emotional response that can then determine the resulting action taken. In other words, this suggests that it is only if unfair treatment threatens one's identity in a group that negative emotion may result. If negative emotion is then not managed appropriately it has the potential to lead to retaliatory behaviour (for similar arguments in the criminology literature see Braithwaite's reintegrative shaming theory and Sherman's defiance theory (Braithwaite, 1989; Ahmed, Harris, Braithwaite \& Braithwaite, 2001; Sherman, 1993). The results from the current study

lend support to this idea by demonstrating that negative emotional responses can mediate the effect of procedural justice on compliance behaviour in both real-life and experimental contexts. Future research may wish to explicitly test the identity-threat/emotion link in these relationships.

\section{Limitations and Future Directions}

Despite the value of our findings to the procedural justice literature, there are some methodological limitations in our study that should be noted and taken into account when 
interpreting the findings. First, data used for analysis in the current project was collected using self-report questionnaires. Although this is a common method for collecting individual perceptions of events and self-reported behaviour, it has implications for participants' interpretability of what is fair treatment, and levels of future compliance. What one individual considers procedurally just, may not be considered so by another. Similarly, compliance was assessed through self-report. What a person says they would do in a given situation is not necessarily what they would do in real-life.

Second, while we found that procedural justice and negative affect were related to compliance, the coefficient sizes reported in Tables 5 and 7 are somewhat weak.

Furthermore, the variation explained in compliance was also somewhat small for the survey data findings. These findings suggest that additional factors not in the model may well explain compliance behaviour more reliably than those contained in the models.

Finally, in Study 2 the vignettes presented to study participants manipulated procedural justice. It is possible that the scenario depicted in the vignette may not represent the realistic behaviour used by police in day-to-day interactions with the public. Furthermore, the sample in Study 2 was a predominantly student sample. Future testing of real-world manipulations of procedural justice would therefore be fruitful for determining how citizens react to police in real settings. For example, researchers in Australia recently worked collaboratively with the Queensland Police Service to manipulate procedural justice during actual police-citizen encounters during randomised breath testing of over 21,000 drivers (see Mazerolle, Bennett, Antrobus \& Eggins, 2012; Mazerolle, Antrobus, Bennett \& Tyler, 2013; Murphy, Mazerolle \& Bennett, 2013). They found that drivers who experienced the procedural justice condition were more satisfied with the encounter, had more trust and confidence in the police officer involved, and were significantly more likely to comply with the officer's instructions when compared to the control group.

\section{Conclusion}

Despite our study's limitations, we have been able to make an important contribution to the procedural justice literature. Our paper builds upon existing research by showing that emotions can mediate the relationship between procedural justice and legal compliance behaviour. This paper has shown for the first time that this can occur within a policing context using both survey and experimental methods. The findings have implications for both theories of procedural justice and for the practice of policing. First, the results suggest that emotion needs to be considered in theoretical models that attempt to explain procedural 
justice effects on behaviour. Second, if police wish to be able to effectively manage citizen behaviour and promote compliance with the law, the findings of the present study suggest that they ought to treat people with procedural justice. By doing so they will be able to mitigate negative emotional reactions to decisions, while at the same time making their job safer through increasing citizen compliance with the law. 


\section{References}

Adams, J. S. (1965). Inequity in social exchange. In L. Berkowitz (Ed.), Advances in Experimental Social Psychology (Vol. 2, pp. 267-299). New York: Academic Press.

Agnew, R. (1992). Foundation for a general strain theory of crime and delinquency. Criminology, 30(1), 47-87.

Agnew, R. (2001). Building on the foundation of general strain theory: Specifying the types of strain most likely to lead to crime and delinquency. Journal of Research in Crime and Delinquency, 38(4), 319-361. doi: 10.1177/0022427801038004001

Ahmed, E., Harris, N., Braithwaite, J., \& Braithwaite, V. (2001). Shame Management through Reintergration. Cambridge, UK: Cambridge University Press.

Baron, R. M., \& Kenny, D. A. (1986). The moderator-mediator variable distinction in social psychological research: conceptual, strategic, and statistical considerations. Journal of Personality and Social Psychology, 51(6), 1173-1182.

Bradford, B., Jackson, J., \& Stanko, E. A. (2009). Contact and confidence: Revisiting the impact of public encounters with the police. Policing and Society, 19(1), 20-46.

Bradford, B., Murphy, K., \& Jackson, J. (2013). Officers as mirrors: Policing, procedural justice and the (re)production of social identity. Social Science Research Network Working Paper No. 2337913.

Braithwaite, J. (1989). Crime, Shame and Reintegration. Cambridge, UK: Cambridge University Press.

Braithwaite, J., \& Makkai, T. (1994). Trust and compliance. Policing and Society, 4(1), 1-12.

Chebat, J. C., \& Slusarczyk, W. (2005). How emotions mediate the effect of perceived justice on loyalty in service recovery situations: an empirical study. Journal of Business Research, 58, 664-673.

Cropanzano, R., Stein, J., \& Nadisic, T. (2011). Social justice and the experience of emotion. New York: Routledge.

Dai, M. (2007). Procedural justice during police-citizen encounters (Doctoral dissertation). Available from ProQuest Dissertations and Theses database.

De Cremer, D., \& Den Ouden, N. (2009). When passion breeds justice: Procedural fairness effects as a function of authority's passion. European Journal of Social Psychology, 39, 384-400.

Giner-Sorolla, R., Mackie, D. M., \& Smith, E. R. (2007). Special issue on intergroup emotions: introduction. Group Processes \& Intergroup Relations, 10(1), 5-8. 
Gordijn, E., Yzerbyt, V., Wigboldus, D., \& Dumont, M. (2006). Emotional reactions to harmful intergroup behaviour. European Journal of Social Psychology, 36, 15-30.

Henderson, H., Wells, W., Maguire, E. R., \& Gray, J. (2010). Evaluating the measurement properties of procedural justice in a correctional setting. Criminal Justice and Behavior, 37(4), 384-399.

Jackson, J., \& Bradford, B. (2010). What is trust and confidence in the police? Policing, 4(3), 241-248.

Jackson, J., Bradford, B., Hough, M., Myhill, A., Quinton, P., \& Tyler, T. R. (2012). Why do people comply with the law? Legitimacy and the influence of legal institutions. British Journal of Criminology, 52(6), 1051-1071. doi: 10.1093/bjc/azs032

Jackson, J., \& Sunshine, J. (2007). Public confidence in policing: a neo-durkheimian perspective. British Journal of Criminology, 47, 214-233.

Johnson, R. R. (2004). Citizen expectations of police traffic stop behavior. Policing, 27(4), 487-497.

Krehbiel, P. J., \& Cropanzano, R. (2000). Procedural justice, outcome favourability and emotion. Social Justice Research, 13(4), 339-360.

Mackie, D. M., Devos, T., \& Smith, E. R. (2000). Intergroup emotions: explaining offensive action tendencies in an intergroup context. Journal of Personality and Social Psychology, 79(4), 602-616.

Mastrofski, S., Reisig, M. \& McCluskey, J. (2002). Police disrespect toward the public: An encounter based analysis. Criminology, 40, 519-552.

Mazerolle, L., Bennett, S., Antrobus, E., \& Eggins, L. (2012). Procedural justice, routine encounters and citizen perceptions of police: Main findings from the Queensland Community Engagement Trial (QCET). Journal of Experimental Criminology, 8, 343-367.

Mazerolle, L., Antrobus, E., Bennett, S. \& Tyler, T. (2013). Shaping citizen perceptions of police legitimacy: A randomized field trial of procedural justice. Criminology, 51, 3363.

McCluskey, J. (2003). Police requests for compliance: Coercive and procedurally just tactics. LFB Scholarly Publishers.

Murphy, K. (2005). Regulating more effectively: the relationship between procedural justice, legitimacy, and tax non-compliance. Journal of Law and Society, 32(4), 562-589.

Murphy, K., Hinds, L., \& Fleming, J. (2008). Encouraging public cooperation and support for police. Policing and Society, 18(2), 136-155. doi:10.1080/10439460802008660 
Murphy, K., Mazerolle, L. \& Bennett, S. (2013). Promoting trust in police: Findings from a randomised experimental trial of procedural justice policing. Policing and Society, Published online 3 December 2013. doi: 10.1080/10439463.2013.862246.

Murphy, K., Murphy, B., \& Mearns, M. (2010a). 'The 2007 public safety and security in Australia survey’: survey methodology and preliminary findings. Alfred Deakin Research Institute Working Paper No. 16. Geelong, NSW: Deakin University. Murphy, K., Murphy, B., \& Mearns, M. (2010b). 'The 2009 crime, safety, and policing in Australia survey': survey methodology and preliminary findings. Alfred Deakin Research Institute Working Paper No. 17. Geelong, NSW: Deakin University.

Murphy, K., \& Tyler, T. (2008). Procedural justice and compliance behaviour: the mediating role of emotions. European Journal of Social Psychology, 38, 652-668.

Potter, P. W. (2005). Procedural justice and voice effects. Proceedings of the Academy of Organizational Culture, Communications and Conflict, 10(1), 51-54.

Queensland Police Service. Annual reports 2003 - 2011. Retrieved from http://www.police.qld.gov.au/services/reportsPublications/annualReport/

Rankin, L. E., \& Tyler, T. R. (2009). Justice and cooperation. Netherlands Journal of Psychology, 65, 146-154.

Schoefer, K., \& Diamantopolous, A. (2008). The role of emotions in translating perceptions of (in)justice into post complaint behavioral response. Journal of Service Research, 11(1), 91-103.

Sherman, L. (1993). Defiance, deterrence, and irrelevance: A theory of the criminal sanction. Journal of Research in Crime and Delinquency, 30, 445-473.

Skarlicki, D. P. \& Folger, R. (1997). Retaliation in the workplace: The roles of distributive, procedural, and interactional justice. Journal of Applied Psychology, 82(3), 434-443.

Smith, E. R. (1993). Social identity and social emotions: toward new conceptualizations of prejudice. In D. M. Mackie \& D. L. Hamilton (Eds.), Affect, cognition and stereotyping: Interactive processes in group perception (pp. 397-315). San Diego, CA: Academic Press.

Sunshine, J., \& Tyler, T. R. (2003). The role of procedural justice and legitimacy in shaping public support for policing. Law \& Society Review, 37(3), 513-547.

Tyler, T. R. (1990). Why People Obey the Law. New Haven: Yale.

Tyler, T. R. (2006). Why People Obey the Law. Princeton, NJ: Princeton University Press.

Tyler, T. R. (2008). Procedural justice and the courts. Court Review, 44, 26-31. 
Tyler, T. R. (2011). Why People Cooperate: The Role of Social Motivations. Princeton, NJ: Princeton University Press.

Tyler, T. R. \& Blader, (2003). The group engagement model: Procedural justice, social identity, and cooperative behavior. Personality and Social Psychology Review, 7, 349361.

Tyler, T. R., \& Huo, Y. J. (2002). Trust in the law: Encouraging public cooperation with the police and courts. New York: Russell Sage.

Tyler, T. R., \& Murphy, K. (2011). Procedural justice, police legitimacy and cooperation with the police: a new paradigm for policing. Australian Research Council Centre of Excellence in Policing and Security Briefing Paper (May issue). Brisbane, QLD: Griffith University.

VanYperen, N. W, Hagedoorn, M., Zweers, M., \& Postma, S. (2000). Injustice and employees' destructive responses: The mediating role of state negative affect. Social Justice Research, 13(3), 291-312.

Weiss, H. M., Suckow, K., \& Cropanzano, R. (1999). Effects of justice conditions on discrete emotions. Journal of Applied Psychology, 84(5), 786-794.

Worsham, R. G. (1996). The effect of tax authority behavior on taxpayer compliance: A procedural justice approach. The Journal of the American Taxation Association, 18(2), 19-39. 
Table 1

Comparison of age, income, gender, and education between full sample surveyed and extracted sample of those who had recent contact with police in prior 12 months.

\begin{tabular}{|c|c|c|c|c|c|c|c|c|c|}
\hline & \multicolumn{3}{|c|}{$\begin{array}{l}\text { Full Sample } \\
(N=1190)\end{array}$} & \multicolumn{3}{|c|}{$\begin{array}{l}\text { Extracted Sample T1 } \\
\qquad(N=401)\end{array}$} & \multicolumn{3}{|c|}{$\begin{array}{l}\text { Extracted Sample T2 } \\
\qquad(N=468)\end{array}$} \\
\hline & $M$ & $S D$ & $\%$ & $M$ & $S D$ & $\%$ & $M$ & $S D$ & $\%$ \\
\hline Age & 56.16 & 15.01 & & 52.61 & 13.78 & & 52.46 & 14.41 & \\
\hline Income (\$’000s) & 82.36 & 55.40 & & 88.32 & 56.55 & & 91.24 & 56.72 & \\
\hline \multicolumn{10}{|l|}{ Gender } \\
\hline Males & & & 45.5 & & & 46.9 & & & 48.3 \\
\hline Females & & & 54.5 & & & 53.1 & & & 51.7 \\
\hline \multicolumn{10}{|l|}{ Education } \\
\hline Year 12 or lower & & & 37.6 & & & 29.2 & & & 31.2 \\
\hline Cert.1 - Adv. Diploma & & & 30.6 & & & 32.5 & & & 32.6 \\
\hline Bachelor Degree or higher & & & 31.8 & & & 38.3 & & & 36.2 \\
\hline
\end{tabular}


Table 2

Factor analysis differentiating Time 2 variables of Procedural Justice, Negative Affect, and Compliance.

\begin{tabular}{|c|c|c|c|}
\hline \multirow[b]{2}{*}{ Item } & \multicolumn{3}{|c|}{ Factor } \\
\hline & 1 & 2 & 3 \\
\hline \multicolumn{4}{|l|}{ 1. Procedural Justice: } \\
\hline \multicolumn{4}{|l|}{ Thinking about your most recent contact with police, were they... } \\
\hline Approachable/friendly & .80 & -.27 & -.07 \\
\hline Polite/respectful/courteous & .80 & -.27 & -.08 \\
\hline Fair & .80 & -.27 & -.09 \\
\hline $\begin{array}{l}\text { Were you given the opportunity to express your views before } \\
\text { decisions were made }\end{array}$ & .72 & -.14 & -.04 \\
\hline Your views were considered when a decision was made & .71 & -.12 & -.01 \\
\hline \multicolumn{4}{|l|}{ 2. Negative Affect: } \\
\hline \multicolumn{4}{|l|}{ When you think about how you were treated by police, do you feel.. } \\
\hline Tense & -.12 & .88 & .09 \\
\hline Anxious & -.10 & .87 & .07 \\
\hline Angry & -.45 & .76 & .05 \\
\hline Resentful & -.45 & .75 & .11 \\
\hline Frustrated & -.45 & .70 & .07 \\
\hline \multicolumn{4}{|l|}{ 3. Compliance: } \\
\hline Disobeying the law is sometimes justified (r) & -.06 & .05 & .88 \\
\hline Disobeying the police is sometimes justified (r) & -.04 & .06 & .83 \\
\hline There are times when it is ok for you to break the law (r) & -.08 & .11 & .81 \\
\hline Eigenvalues (before rotation) & 5.69 & 2.02 & 1.48 \\
\hline Explained variance after rotation (\%) & 27.56 & 26.38 & 16.71 \\
\hline
\end{tabular}

Note: Principal Components Analysis, varimax rotation; (r) denotes recoding of original survey item 


\section{Table 3}

Means, 95\% confidence intervals, and bi-variate correlation matrix between Time 1 and Time 2 scales of Study 1

\begin{tabular}{lccccccc}
\hline Scale & Mean & $95 \%$ CI & 1 & 2 & 3 & 4 & 5 \\
\hline & & & & & & & \\
\hline 1. Procedural Justice T1 & 3.94 & {$[3.88,4.00]$} & $(0.90)$ & $0.32^{* *}$ & $-0.59^{* *}$ & $-0.30^{* *}$ & $0.18^{* *}$ \\
2. Procedural Justice T2 & 3.64 & {$[3.58,3.69]$} & & $(0.87)$ & $-0.27^{* *}$ & $-0.55^{* *}$ & $0.17^{* *}$ \\
3. Negative Affect T1 & 1.86 & {$[1.78,1.94]$} & & & $(0.94)$ & $0.31^{* *}$ & $-0.16^{* *}$ \\
4. Negative Affect T2 & 2.10 & {$[2.03,2.17]$} & & & $(0.91)$ & $-0.18^{* *}$ \\
5. Compliance T2 & 3.22 & {$[3.16,3.28]$} & & & & $(0.78)$ \\
\hline
\end{tabular}

Figures in parentheses are Cronbach alpha coefficients. ${ }^{* *} p<.01$ 
Table 4

Cross-sectional OLS regression analysis showing how demographic variables and procedural justice predict negative affect.

\begin{tabular}{lcccc}
\hline & \multicolumn{5}{c}{ Step 1} \\
\cline { 2 - 5 } Predictor & $B$ & $S E_{B}$ & $\beta$ & $r^{2}$ part \\
\hline Age & -0.01 & 0.00 & $-0.12^{* *}$ & 0.02 \\
Gender (0 = Male) & 0.00 & 0.08 & 0.00 & \\
Education & -0.01 & 0.02 & -0.03 & \\
Income & 0.00 & 0.00 & -0.01 & \\
Procedural Justice & -0.80 & 0.05 & $-0.63^{* * *}$ & 0.40 \\
Constant & 5.48 & 0.27 & & \\
& & & & \\
$R^{2}$ & & 0.42 & & \\
$R^{2}$ change & & 0.42 & & \\
$F$ change & & $49.52^{* * *}$ & & \\
$d f$ & 5,344 & & \\
\hline${ }^{*} p<.05 ;{ }^{* *} p<.01 ; * * * p<.001$ & & &
\end{tabular}


Table 5

Cross-sectional hierarchical regression analysis exploring the meditating role of negative affect in the procedural justice/compliance relationship. Dependent variable is compliance (a higher score on the compliance measure reflects a stronger propensity to obey the law).

\begin{tabular}{|c|c|c|c|c|c|c|c|}
\hline \multirow[b]{2}{*}{ Predictor } & \multicolumn{3}{|c|}{ Step 1} & \multicolumn{3}{|c|}{ Step 2} & \multirow[b]{2}{*}{$r_{p a r}^{2}$} \\
\hline & $B$ & $S E_{B}$ & $B$ & $B$ & $S E_{B}$ & $\beta$ & \\
\hline Age & 0.01 & 0.00 & $0.12^{*}$ & 0.01 & 0.00 & 0.10 & \\
\hline Gender ( $0=$ Male) & 0.09 & 0.08 & 0.06 & 0.09 & 0.08 & 0.06 & \\
\hline Education & -0.04 & 0.02 & $-0.12^{*}$ & -0.04 & 0.02 & $-0.12 *$ & 0.01 \\
\hline Income & 0.00 & 0.00 & 0.03 & 0.00 & 0.00 & 0.03 & \\
\hline Procedural Justice & 0.14 & 0.06 & $0.13^{*}$ & 0.04 & 0.07 & 0.03 & \\
\hline Negative Affect & & & & -0.13 & 0.06 & $-0.15^{*}$ & 0.01 \\
\hline Constant & 2.53 & 0.29 & & 3.23 & 0.43 & & \\
\hline$R^{2}$ & & 0.05 & & & 0.06 & & \\
\hline$R^{2}$ change & & 0.05 & & & 0.01 & & \\
\hline$F$ change & & $3.62 * *$ & & & $4.79 *$ & & \\
\hline$d f$ & & 5,343 & & & 1,342 & & \\
\hline
\end{tabular}

${ }^{*} p<.05 ; * * p<.01 ; * * * p<.001$ 
Table 6

Longitudinal OLS regression analysis showing how demographic variables, procedural justice, and negative affect at Time 1 predict negative affect at Time 2.

\begin{tabular}{lcccc}
\hline & \multicolumn{5}{c}{ Step 1 } \\
\cline { 2 - 5 } Predictor & $B$ & $S E_{B}$ & $\beta$ & $r^{2}$ part \\
\hline Age T1 & -0.01 & 0.00 & -0.10 & \\
Gender T1 (0 = Male) & -0.10 & 0.11 & -0.06 & \\
Education T1 & 0.02 & 0.03 & 0.05 & \\
Income T1 & 0.00 & 0.00 & -0.07 & 0.02 \\
Negative Affect T1 & 0.16 & 0.07 & $0.17^{*}$ & 0.05 \\
Procedural Justice T1 & -0.33 & 0.09 & $-0.27^{* * *}$ & \\
Constant & 3.51 & 0.53 & & \\
& & & & \\
$R^{2}$ & & 0.18 & & \\
$R^{2}$ change & & 0.18 & & \\
$F$ change & & $8.79^{* * *}$ & & \\
$d f$ & & 6,239 & & \\
\hline
\end{tabular}

${ }^{*} p<.05 ; * * p<.01 ; * * * p<.001$ 


\section{Table 7}

Longitudinal hierarchical regression analysis exploring the meditating role of negative affect on the procedural justice/compliance relationship. Dependent variable is compliance ( higher score on the compliance measure reflects a stronger propensity to obey the law).

\begin{tabular}{|c|c|c|c|c|c|c|c|}
\hline \multirow[b]{2}{*}{ Predictor } & \multicolumn{3}{|c|}{ Step 1} & \multicolumn{3}{|c|}{ Step 2} & \multirow[b]{2}{*}{$r_{\text {part }}^{2}$} \\
\hline & $B$ & $S E_{B}$ & $\beta$ & $B$ & $S E_{B}$ & $\beta$ & \\
\hline Age T1 & 0.01 & 0.00 & 0.10 & 0.01 & 0.00 & 0.08 & \\
\hline Gender T1 (0 = Male) & 0.13 & 0.10 & 0.08 & 0.11 & 0.10 & 0.07 & \\
\hline Education T1 & -0.04 & 0.02 & -0.10 & -0.03 & 0.02 & -0.09 & \\
\hline Income $\mathrm{T} 1$ & 0.00 & 0.00 & -0.05 & 0.00 & 0.00 & -0.07 & \\
\hline Negative Affect T1 & -0.08 & 0.07 & -0.10 & -0.05 & 0.06 & -0.06 & \\
\hline Procedural Justice T1 & 0.23 & 0.09 & $0.21^{* *}$ & 0.17 & 0.09 & 0.15 & \\
\hline Negative Affect T2 & & & & -0.21 & 0.06 & $-0.23 * * *$ & 0.05 \\
\hline Constant & 2.39 & 0.50 & & 3.12 & 0.53 & & \\
\hline$R^{2}$ & & 0.12 & & & 0.16 & & \\
\hline$R^{2}$ change & & 0.12 & & & 0.04 & & \\
\hline$F$ change & & $5.46^{*}$ & & & $11.83 * * *$ & & \\
\hline$d f$ & & 6,238 & & & 1,237 & & \\
\hline
\end{tabular}

${ }^{*} p<.05 ; * * p<.01 ; * * * p<.001$ 
Table 8

Factor analysis differentiating Negative Affect and Compliance variables for Study 2.

\begin{tabular}{|c|c|c|}
\hline \multirow[b]{2}{*}{ Item } & \multicolumn{2}{|c|}{ Factor } \\
\hline & 1 & 2 \\
\hline \multicolumn{3}{|l|}{ 1. Negative Affect: } \\
\hline \multicolumn{3}{|c|}{ When you think about how you were treated by police, do you feel.. } \\
\hline Frustrated & .89 & -.21 \\
\hline Tense & .87 & -.10 \\
\hline Angry & .87 & -.27 \\
\hline Resentful & .85 & -.24 \\
\hline Anxious & .79 & .02 \\
\hline \multicolumn{3}{|l|}{ 2. Compliance: } \\
\hline \multicolumn{3}{|l|}{ In the future, would such an experience make you... } \\
\hline More careful about following all road rules & -.18 & .92 \\
\hline More careful about doing the correct speed limit & -.08 & .86 \\
\hline Want to follow the law all of the time & -.19 & .85 \\
\hline More willing to follow the law in general & -.13 & .82 \\
\hline Eigenvalues (before rotation) & 4.66 & 2.22 \\
\hline Explained variance after rotation (\%) & 41.49 & 34.98 \\
\hline
\end{tabular}

Note: Principal Components Analysis, varimax rotation. 
Table 9

Means and 95\% Confidence Intervals for Negative Affect and Compliance for each condition of Procedural Justice.

\begin{tabular}{|c|c|c|c|c|}
\hline & \multicolumn{2}{|c|}{ Negative Affect } & \multicolumn{2}{|c|}{ Compliance } \\
\hline & Mean & $95 \% \mathrm{CI}$ & Mean & $95 \% \mathrm{CI}$ \\
\hline Procedural Justice & 2.42 & {$[2.21,2.62]$} & 3.72 & {$[3.55,3.89]$} \\
\hline Procedural Injustice & 4.06 & {$[3.92,4.19]$} & 3.22 & {$[3.00,3.43]$} \\
\hline
\end{tabular}


Table 10

OLS regression analysis showing how demographic variables and procedural justice predict negative affect when procedural justice is manipulated under controlled conditions.

\begin{tabular}{lcccc}
\hline & \multicolumn{5}{c}{ Step 1} \\
\cline { 2 - 5 } Predictor & $B$ & $S E_{B}$ & $\beta$ & $r^{2}$ part \\
\hline Age & 0.00 & 0.01 & 0.01 & \\
Gender $(0=$ Male) & -0.08 & 0.16 & -0.03 & \\
Income & -0.02 & 0.04 & -0.04 & \\
Procedural Justice (0 = No PJ) & -1.71 & 0.13 & $-0.75^{* * *}$ & 0.54 \\
Constant & 4.06 & 0.28 & & \\
& & & & \\
$R^{2}$ & & 0.55 & & \\
$R^{2}$ change & & 0.55 & & \\
$F$ change & & $42.30^{* * *}$ & & \\
$d f$ & & 4,139 & & \\
\hline$* p<.05 ; * *<.01 ; * * *<.001$ & &
\end{tabular}

${ }^{*} p<.05 ;{ }^{* *} p<.01 ; * * * p<.001$ 
Table 11

Hierarchical regression analysis exploring the meditational role of negative affect in the relationship between procedural justice and compliance with the law when procedural justice is manipulated under controlled conditions. Dependent variable is compliance (a higher score on the compliance measure reflects a stronger willingness to obey the law).

\begin{tabular}{|c|c|c|c|c|c|c|c|}
\hline \multirow[b]{2}{*}{ Predictor } & \multicolumn{3}{|c|}{ Step 1} & \multicolumn{3}{|c|}{ Step 2} & \multirow[b]{2}{*}{$r_{p a r t}^{2}$} \\
\hline & $B$ & $S E_{B}$ & $\beta$ & $B$ & $S E_{B}$ & $B$ & \\
\hline Age & 0.02 & 0.01 & 0.17 & 0.02 & 0.01 & 0.17 & \\
\hline Gender ( $0=$ Male) & 0.26 & 0.18 & 0.12 & 0.24 & 0.17 & 0.11 & \\
\hline Income & -0.05 & 0.04 & -0.12 & -0.06 & 0.04 & -0.14 & \\
\hline Procedural Justice $(0=$ No PJ) & 0.52 & 0.14 & $0.29 * * *$ & 0.12 & 0.21 & 0.07 & \\
\hline Negative Affect & & & & -0.23 & 0.09 & $-0.30 * *$ & 0.05 \\
\hline Constant & 2.69 & 0.30 & & 3.64 & 0.47 & & \\
\hline$R^{2}$ & & 0.12 & & & 0.16 & & \\
\hline$R^{2}$ change & & 0.12 & & & 0.04 & & \\
\hline$F$ change & & $4.77^{* * *}$ & & & $6.84^{* *}$ & & \\
\hline$D f$ & & 4,139 & & & 1,138 & & \\
\hline
\end{tabular}

${ }^{*} p<.05 ;{ }^{* *} p<.01 ; * * * p<.001$ 